\title{
Use of porcine dermal collagen as a prosthetic mesh in a contaminated field for ventral hernia repair: a case report
}

\author{
T. M. Saettele $\cdot$ S. L. Bachman $\cdot$ C. R. Costello $\cdot$
}

S. A. Grant • D. S. Cleveland · T. S. Loy •

D. G. Kolder · B. J. Ramshaw

Published online: 12 May 2007

(C) Springer-Verlag 2007

\section{Erratum to: Hernia}

\section{DOI 10.1007/s10029-006-0186-z}

Unfortunately, Fig. $7 \mathrm{~b}$ was not exchanged as requested by the author. The correct Fig. 7a, b is given here.

Fig. 7 a Scanning electron microscopy (SEM) of pristine polypropylene mesh from a Composix mesh at $\times 200$. b SEM of polypropylene from the explanted mesh at $\times 200$. The surface has been altered with respect to the pristine material, with evidence of blistering and increased surface roughness, possibly due to oxidation
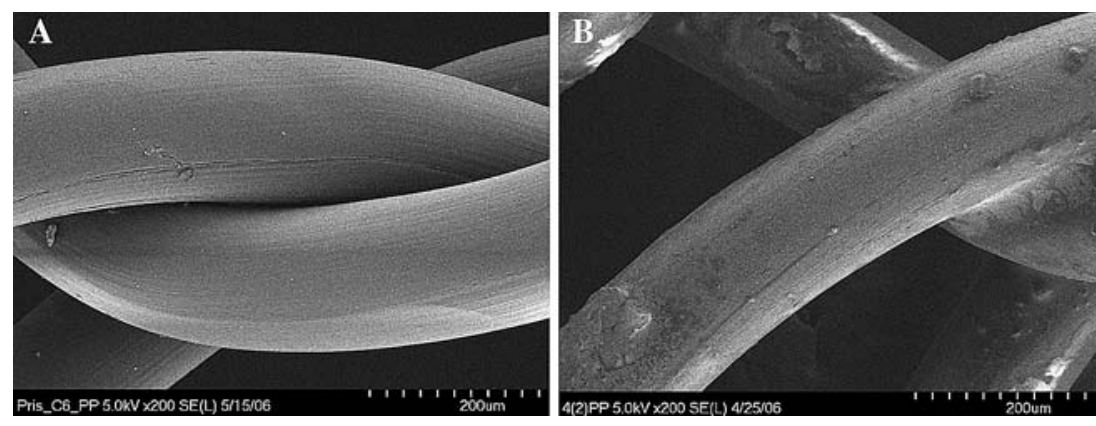

The online version of the original article can be found at http://dx.doi.org/10.1007/s10029-006-0186-z.

T. M. Saettele · S. L. Bachman · D. G. Kolder · B. J. Ramshaw ( $₫)$

Department of General Surgery,

University of Missouri-Columbia,

Mc414 McHaney Hall,

Columbia, MO 65212, USA

e-mail: ramshawb@health.missouri.edu

C. R. Costello $\cdot$ S. A. Grant

Department of Biological Engineering,

University of Missouri-Columbia, Columbia, MO, USA

D. S. Cleveland · T. S. Loy

Department of Pathology and Anatomical Sciences,

University of Missouri-Columbia, Columbia, MO, USA 